\title{
Association of Antineuronal Antibody Levels with Cognitive Impairment in Older Cuban Adults
}

\author{
Leonardo Cristiá-Lara, Saily Sosa-Pérez MD MS, Nelky Urrutia-Amble, Alia Garrudo-Guirado, Aimé Posada-García, \\ Lídice Galán-García PhD, Levis Verde-Corvo MS, Madelín Rodríguez-Morera MD MS, Miriam Dorestes-Brown, \\ Maria Antonieta Bobes-León PhD, Chryslaine Rodríguez-Tanty PhD, Marquiza Sablón-Carrazana PhD, Viana Manrique-Suárez MS
}

\begin{abstract}
INTRODUCTION Alzheimer disease is the main cause of dementia associated with aging in Cuba and the world. Development of methods for early diagnosis is vital to increasing intervention effectiveness and improving patient quality of life. Recent studies have shown associations between alterations in serum levels of antineuronal antibodies and Alzheimer disease pathology. However, the specific relationship between such antineuronal antibodies and Alzheimer pathogenesis remains unclear because of the great variety of antibodies identified and their heterogeneity among patients and nondemented controls.
\end{abstract}

OBJECTIVE Assess the association between serum levels of antibodies against neuronal antigens (total brain protein, aldolase and amyloid beta protein) and cognitive performance in older Cuban adults.

METHODS A cross-sectional pilot study was conducted of adults aged $\geq 65$ years living in Havana's Playa Municipality and Artemisa Province (southwest of Havana). A sociodemographic and risk factor questionnaire was administered, neuropsychological assessment conducted, and physical and neurological examinations performed. A relative or caregiver was also interviewed. Laboratory tests included: complete blood count, glycemia, lipid panel, and apolipoprotein E genotype. Of 143 individuals studied, 33 were cognitively normal, 52 had mild cognitive impairment, and

\section{INTRODUCTION}

Dementia is considered the epidemic of the 21 st century, and its main risk factor is advanced age. With rapid population aging, the burden of neurodegenerative diseases has increased, including dementia and, particularly, Alzheimer disease (AD), its most common form.[1-3]

$A D$ is a chronic neurodegenerative disease that progressively impairs cognitive function.[3] Its clinical symptoms include memory loss, language disorders, visual, spatial and behavioral changes. Although various symptoms may occur, memory is always affected. Autopsy with neuropathological examination is the gold standard for $A D$ diagnosis. $A D$ neuropathology is characterized by extracellular deposits of amyloid beta peptide $(A \beta)$ in nerve tissue called amyloid or senile plaques, and intracellular deposits of hyperphosphorylated tau protein, known as neurofibrillary tangles.[4]

Diagnosis of probable AD ( $P A D)$ is based on criteria adopted by the US National Institute of Neurological and Communicative Disorders and Stroke and the Association of Alzheimer's Disease and Related Disorders (NICNDS-ADRDA)[5] and DSM-IV.[6] Patients should have a mini mental state examination score (MMSE) of 0-23 (maximum 30)[7] and a clinical dementia rating (CDR) of 1-3 (1 = mild dementia).[8] These criteria have been used for $p A D$ diagnosis for $>30$ years in clinical studies with $87 \%$ sensitivity and $70 \%$ specificity.[9] The most documented genetic
58, probable Alzheimer disease. Serum antibody levels were determined by ELISA and compared using covariance analysis with a significance level of 0.05 . ELISA specificity, sensitivity and predictive value were assessed by analyzing their respective diagnostic performance curves.

RESULTS Patients with probable Alzheimer disease performed least well on the mini mental state examination (cognitively normal 28.8, SD 1.2; mild cognitive impairment 27.4, SD 2.2; probable Alzheimer disease 12.9, SD 6.5; ANOVA $p$ <0.001). The percentage of Apo E4 carriers was seven times greater in the group with probable Alzheimer disease than in the cognitively normal group. Among the antibodies studied, only those against amyloid beta peptide had levels significantly higher in the Alzheimer disease group than in the cognitively normal group $(p=0.007)$ and the group with mild cognitive impairment $(p=0.002)$.

CONCLUSIONS Results support the presence of an autoimmune component in Alzheimer disease and suggest that serum anti-amyloid-beta could be used for its diagnosis.

KEYWORDS Dementia, Alzheimer disease, mild cognitive impairment, autoantibodies, E4 apolipoprotein, Apo E4, enzymelinked immunosorbent assay, ELISA, immunoassay, immunosorbent techniques, amyloid beta protein, Cuba

risk factor for this disease is the $\varepsilon 4$ allele of apolipoprotein $E$, Apo E4.[10]

Dementia afflicts 46.8 million people worldwide (approximately $0.5 \%$ of the population) and the number is expected to almost double every 20 years, reaching 74.7 million by 2030 and 131.5 million by 2050 . There are more than 9.9 million new cases of dementia every year, a new case every 3.2 seconds. The World Alzheimer Report 2015 estimated social and economic costs of dementia at US\$818 billion, and predicted these would reach US\$1 trillion by 2018.[1]

Cuba is the second oldest country in Latin America, with approximately $19 \%$ of its population aged $\geq 60$ years.[11] By 2020, 1 in 4 Cubans will be aged $\geq 60$ years[12] and about half a million will be aged $>80$ years.[13] This implies that aging-related diseases such as $A D$ will become a major challenge for the public health system. Cuban studies estimate that 1 in 10 people aged $\geq 65$ years develops some sort of dementia, of which $A D$ is the most common.[14-19]

About 150,000 Cubans suffer from $A D$ or related dementia and an increase to 273,000 cases is expected in 2030 and to 440,000 , in 2050 . Dementia prevalence currently ranges from $6.4 \%$ to $10.2 \%$ in people aged $\geq 65$ years,[16] for an incidence of $21.8 / 1000 /$ year. $[17,19,20]$ Annual mortality among people with dementia is $195.5 / 1000 .[20]$ 
Current concepts of $A D$ pathogenesis include involvement of inflammatory and autoimmune components.[21,22] Several studies have reported immunopositivity to neurons in histological brain sections of AD patients, a fact rarely observed in the same brain regions of age-matched nondemented controls.[22,23] Because neuronal antibodies (Abs) are abundant and common in human sera, to the extent that they have been detected in young nondemented individuals,[23] it may well be that these can only contribute to $A D$ pathogenesis if there is dysfunction of the blood-brain barrier, allowing passage into brain tissue.[22-25] A relationship has been demonstrated between AD development and titers of autoantibodies to certain biomolecules.[26-33]

$A \beta$ plaques are generally considered to be associated with neuronal impairment and loss of synapses.[33,34] Antibodies against total brain protein (TBP) have been shown to penetrate the blood-brain barrier and promote intraneuronal $A \beta$ deposition. [23] Several studies have found altered serum levels of antiTBP in AD patients.[34] These include: anti-A $\beta,[30-32]$ antineurotransmitters, anti-S100, antiglial fibrillary acidic protein,[26] antialdolase (anti-ALD),[27] antiganglioside GM1[28] and antioxidized low-density lipoproteins.[29] Because results of different studies are inconsistent, it is difficult to establish a relationship between these autoantibody levels, cognitive impairment and $A D$ diagnosis.[35]

It is not clear whether autoantibodies play a pathogenic and causal role or simply occur as a consequence of disease progression. There would be obvious benefits to identification of an antibody or combination of Abs as diagnostic biomarkers for $A D$.

Current $A D$ biomarker candidates are either expensive, such as magnetic resonance imaging[36] and positron emission tomography,[37] or invasive, such as those requiring lumbar puncture to collect cerebrospinal fluid (CSF).[38] Although considerable progress has been made in demonstrating these biomarkers' relationships to AD pathophysiology,[39] less costly and invasive biomarkers (blood, serum) for predicting disease progression are urgently needed. This study's objective was to assess the association of serum levels of Abs against neuronal antigens (TBP, ALD and $A \beta$ ) with cognitive performance in Cubans aged $\geq 65$ years, to explore their potential utility as AD biomarkers.

\section{METHODS}

Study design and population This was a cross-sectional pilot study of adults aged $\geq 65$ years living in Havana's Playa Municipality and in Artemisa Province, immediately southwest of Havana. Methods for data collection and neuropsychological assessment have been published previously for the Playa Dementia and Alzheimer Study (EDAP),[15] carried out in September-December 2003 under the National Program for Care of Persons with Disabilities to estimate incidence of $A D$ and other dementias, as well as their risk factors.

Written informed consent was obtained from participants or a relative or caregiver (informant), who could corroborate or provide information requested during assessment. Clinical evaluation was performed by a physician and another team member (a psychologist or disability specialist). A sociodemographic and risk factor questionnaire was administered, neuropsychological assessment conducted, physical and neurological examinations performed, and a relative or caregiver interviewed. Laboratory tests included complete blood count, glycemia, lipid panel and apolipoprotein E genotype.[40]

Data and blood samples for the Playa group came from 74 EDAP participants[15] randomly selected for a study of the association between Apo E4 and cognitive impairment.[41] From September 2012 through May 2014, the Provincial Service for Comprehensive Community Care of Memory Disorders in San Antonio de los Baños (Artemisa Province) used EDAP methods to assess 270 patients, 146 of whom provided blood samples. The Cuban Neuroscience Center (CNEURO) collected blood for genetic and immunological testing in both Playa and Artemisa. In all, 344 patients were examined, only 220 of whom provided blood samples. Lack of reagents made it impossible to test all available samples, so our analysis is based on 143 participants and their samples, 72 from Playa and 71 from Artemisa.

Diagnosis Neurologically and psychiatrically normal subjects, without any cognitive deficit were considered cognitively normal (CN). Mild cognitive impairment $(\mathrm{MCl})$ was diagnosed by Petersen's criteria:[42]

- memory alteration, corroborated by a caregiver;

- memory alteration documented with tests and specific scales;

- preservation of general cognitive function;

- preservation of activities of daily living; and

- nonfulfillment with DSM-IV dementia criteria[6]

Patients with pAD were diagnosed according to NICNDSADRDA[5] and DSM-IV[6] criteria. MMSE scores ranged from 0 to 23 points and CDRs from 1 to 3 . In general, these criteria include:

- onset and progression of insidious dementia, which interferes with activities of daily living;

- absence of other systemic or cerebral disease explaining the symptoms;

- clinically established dementia, documented by psychological testing;

- deficits in two or more areas of knowledge;

- progressive memory and other cognitive function impairment, and

- lack of alteration in level of consciousness (patient awake, with no impairment of consciousness, even drowsiness or confusion).

Among 143 participants assessed, 33 were diagnosed as $\mathrm{CN} ; 52$, with $\mathrm{MCl}$ and 58, with pAD.

Variables Independent variables were age (years); MMSE score; sex; education (years completed); skin color (white, nonwhite); serum levels of anti-TBP, anti-ALD, and anti-A $\beta$, expressed in optical density units $\left(O D_{492 n m}\right)$; and serum positivity for the same three Abs.

According to Marcheco-Teruel's 2011 report, in Cuba individuals perceived as mestizo and black show the greatest proportion of African ancestry; while those perceived as white have the least.[18] Although the relationship between immunological status and ethnicity remains unclear, it has been reported that autoimmune diseases are more common and severe in Afrodescendant individuals.[43] Therefore, in order to determine, in a simple way, the existence of possible interactions between ethnicity and serum Abs levels assessed 
in the study, the sample was divided by skin color, into white (suggesting a lower proportion of African ancestry) and nonwhite (mestizo and black, suggesting a higher proportion of African ancestry), instead of the usual classification (white, mestizo, and black) used in Cuba's census.

Obtaining neuronal antigens Brain antigens were extracted from the brains of adult male Wistar rats by homogenization of tissue previously frozen at $-70{ }^{\circ} \mathrm{C}$ in extraction buffer ( $2 \%$ SDS, $10 \%$ glycerol, $5 \%$ 2-mercaptoethanol and $0.125 \mathrm{~mol} / \mathrm{L}$ Tris $\mathrm{HCl}$, $\mathrm{pH}$ 6.8). The homogenized tissue was centrifuged at $10,000 \mathrm{~g}$ for $10 \mathrm{~min}$ and the supernatant recovered.[44]

Determination of serum anti-TBP and anti-ALD levels Serum levels of anti-TBP and anti-ALD were assessed by indirect ELISA as described previously.[27,45] The 96-well plates were coated overnight at $4{ }^{\circ} \mathrm{C}$ with $100 \mu \mathrm{L}$ of antigen-1 $\mu \mathrm{g} / \mathrm{mL}$ total brain protein extract or $2 \mu \mathrm{g} / \mathrm{mL}$ aldolase $\mathrm{C}$ (Sigma Aldrich, USA)-diluted in carbonate-bicarbonate coating buffer $\left(\mathrm{Na}_{2} \mathrm{CO}_{3} /\right.$ $\mathrm{NaHCO}_{3}, \mathrm{pH}$ 9.6). After washing the plate with $0.05 \% \mathrm{H}_{2} \mathrm{O}$ Tween 80 (volume:volume, v:v), it was blocked with $120 \mu \mathrm{L}$ of $5 \%$ skim milk solution (mass:volume) in 1X PBS and incubated for 1 hour at $37^{\circ} \mathrm{C}$. The plate was washed and $100 \mu \mathrm{L}$ of each serum, diluted 1:300 (v:v) in 0.05\% PBS-Tween 80 , were added into each well, in triplicate, and incubated for 1 hour at $37^{\circ} \mathrm{C}$. The presence of Abs was detected by a 1/5000 conjugate of antihuman IgG peroxidase (PA1-28647, Thermo Scientific, USA) in $1 \%$ skim milk in PBS-Tween and incubated for 1 hour at $37^{\circ} \mathrm{C}$. Finally, the plate was washed with $0.05 \% \mathrm{H}_{2} \mathrm{O}$-Tween 80 (v:v), and $100 \mu \mathrm{L}$ of developing solution $(0.01 \%$ o-phenylenediamine, OPD; $0.03 \% \mathrm{H}_{2} \mathrm{O}_{2}, \mathrm{v}: \mathrm{v}$, in substrate buffer) were added and dark-incubated at room temperature for 15 minutes until color development. To stop the reaction, $50 \mu \mathrm{L}$ of $2.5 \mathrm{~mol} / \mathrm{L}$ sulfuric acid was added. $O D_{492 \mathrm{~nm}}$ was recorded on a Suma ELISA plate reader (TecnoSuma International, Cuba). Sera were considered positive if $O D_{492 n m}$ exceeded the $C N$ group's mean $O D_{492 n m}$ by 1.5 SD.

Determination of serum anti-A $\beta$ levels Serum anti-A $\beta$ levels were assessed by ELISA sandwich assays[46] designed for this purpose. The 96 -well plates were coated overnight at $4{ }^{\circ} \mathrm{C}$ with $100 \mu \mathrm{L}$ of human anti-A $\beta$ (1-42) (A3981, Sigma Aldrich, USA), diluted $1 / 10,000$ in carbonate-bicarbonate coating buffer $\left(\mathrm{Na}_{2} \mathrm{CO}_{3} / \mathrm{NaHCO}_{3}, \mathrm{pH}\right.$ 9.6). After washing the plate with $0.05 \%$ $\mathrm{H}_{2} \mathrm{O}$-Tween $80(\mathrm{v}: \mathrm{v})$, it was blocked with $120 \mu \mathrm{L}$ of $5 \%$ skim milk solution (m:v) in $1 \mathrm{X}$ PBS and incubated for 1 hour at $37^{\circ} \mathrm{C}$. The plate was washed and incubated for 1 hour at $37^{\circ} \mathrm{C}$ with 100 $\mu \mathrm{L}$ of rat total brain protein extract with $1 \mu \mathrm{g} / \mathrm{mL}$ concentration. The plate was washed and $100 \mu \mathrm{L}$ of serum diluted 1/200 in $0.05 \%$ PBS-Tween 80 (v:v) were added, in triplicate. It was incubated for 1 hour at $37^{\circ} \mathrm{C}$. The presence of Abs was detected by a conjugate of anti-human IgG with 1/5000 peroxidase (PA128647, Thermo Scientific, USA) in $1 \%$ skim milk in PBS-Tween, incubated for 1 hour at $37^{\circ} \mathrm{C}$. Finally, the plate was washed with $0.05 \% \mathrm{H}_{2} \mathrm{O}$-Tween 80 (v:v) and $100 \mu \mathrm{L}$ of developing solution (0.01\% OPD; $0.03 \% \mathrm{H}_{2} \mathrm{O}_{2}, \mathrm{v}: \mathrm{v}$, in substrate buffer) were added, and dark-incubated at room temperature for 15 minutes until color development. To stop the reaction, $50 \mu \mathrm{L}$ of $2.5 \mathrm{~mol} / \mathrm{L}$ sulfuric acid were added. $\mathrm{OD}_{492 \mathrm{~nm}}$ was recorded on a Suma ELISA plate reader (TecnoSuma International, Cuba). Sera were considered positive if $\mathrm{OD}_{492 \mathrm{~nm}}$ exceeded the $\mathrm{CN}$ group's mean $\mathrm{OD}_{492 \mathrm{~nm}}$ by $1.5 \mathrm{SD}$.
Analysis A significance threshold of $p=0.05$ was selected. Normality of continuous variables was tested using the Kolmogorov-Smirnov test. The means for age and years of schooling were compared using one-way analysis of variance (ANOVA). Comparison of mean autoantibody levels was performed by covariance analysis (ANCOVA), which included age as covariate, taking into account that an increase of autoantibody levels occurs with age, an effect not reported for the other demographic variables studied.[47] For analysis of mean MMSE values by ANCOVA, age and years of education were included, since both variables are known to affect MMSE scores.[48] In cases where a significant effect was detected in ANOVA, the Duncan multiple-rank test was used to identify diagnostic groups that differed from each other. Differences in discrete variable distribution were analyzed using the chi-square test. Receiver operating characteristic curves (ROC) were used to assess predictive power of the parameters obtained in ELISA; the area under the curve (AUC) was used as a measure of discrimination between groups. Hypothesis testing was done according to Hanley and McNeil's methodology.[49] Diagnostic reference criteria for cognitively normal individuals, mild cognitive impairment and probable $A D$ are provided in the section describing participants. Software packages used were STATISTIC 8.0 and MedCalc 16.2.

Ethics The research protocol was approved by the CNEURO's Scientific Council and by the Ethics Committee of the National Program for Care of Persons with Disabilities. Participants and/or informants gave informed consent after being provided detailed information about the study's purpose, procedures and followup, and reassurance that their care would not be affected if they chose not to participate in (or remain in) the study. Data management procedures ensured confidentiality of participant information.

\section{RESULTS}

Sample characteristics Table 1 shows mean values for continuous variables and the distribution of discrete variables. Also included is the percentage of individuals in each group with Apo E4. Normality of distribution was confirmed for continuous variables. The Kolmogorov-Smirnov test obtained nonsignificant $p$ values for age (0.257), education (0.074), and serum anti-ALD (0.102), anti-A $\beta(0.053)$ and anti-TBP (0.66).

No statistically significant differences were found between mean ages of the $\mathrm{CN}$ and $\mathrm{MCl}$ groups ( $\mathrm{CN} 71.0$, SD 4.9; $\mathrm{MCl} 73.2$, SD 4.9; Duncan multiple-rank test $p=0.077$ ). However, there were significant differences between the pAD group's mean age and those of the $\mathrm{CN}$ and the $\mathrm{MCl}$ group (76.9, SD 6.8; ANOVA $p<0.001)$.

There were no significant differences between diagnostic groups in percentages of men and women $\left(X^{2}=0.05\right.$, df $\left.=2, p=0.777\right)$. Mean educational level in the sample was 7.65 years, SD 4.21; it was significantly higher in the $\mathrm{CN}$ group than in the $\mathrm{MCl}$ and $\mathrm{pAD}$ groups (CN: 10.6, SD 4.5; MCl: 6.9, SD 4.0; pAD: 6.6, SD 3.6; ANOVA, $\mathrm{p}<0.001)$. The latter two did not show significant differences with respect to age (Duncan multiple-rank test, $p=0.743$ ).

Although white skin color predominated in all groups, the proportions of white and nonwhite individuals were significantly different among the three diagnostic groups $\left(X^{2}=14.13\right.$, df $=2$, 
Table 1: Sample characteristics by diagnostic group

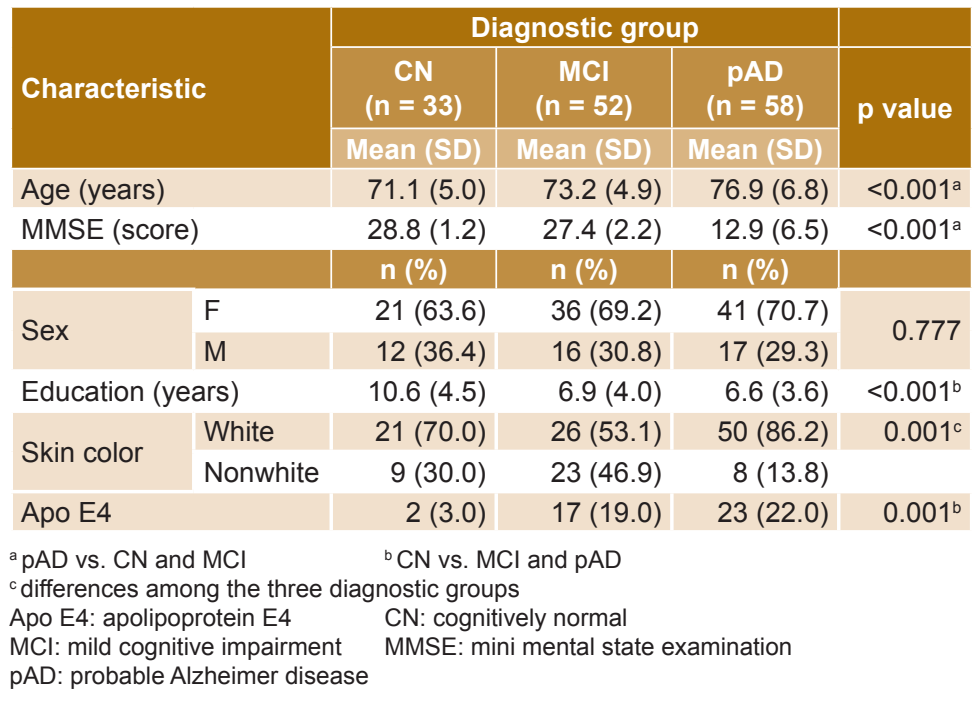

$p<0.001)$. A higher proportion of individuals with white skin color was observed in the $\mathrm{pAD}$ and $\mathrm{CN}$ groups, especially in the former. Meanwhile, in the $\mathrm{MCl}$ group, white skin color was slightly more common than nonwhite.

Patients with pAD had the lowest MMSE scores (CN: 28.8, SD 1.2; MCl: 27.4, SD 2.2; pAD: 12.9, SD 6.5; ANOVA, $p<0.001$ ). Finally, there was a significantly higher frequency of Apo $\mathrm{E} 4$ in both the $\mathrm{MCl}$ and the $\mathrm{pAD}$ groups $\left(\mathrm{X}^{2}=14.44\right.$, df $=2$, $p=0.001$ ) compared to $\mathrm{CN}$.

Serum anti-TBP, anti-A $\beta$ and anti-ALD levels Age was considered a covariate in comparison of serum antibody levels. Serum anti-TBP levels did not differ significantly among the three diagnos- tic groups (mean, SD: CN 0.061, 0.055; MCI 0.071, 0.063; pAD $0.090,0.085 ;$ ANCOVA, $p=0.321$ ). There were no significant differences in serum levels of anti-ALD (mean, SD: CN 0.077, 0.042; MCl 0.095, 0.060; pAD 0.129, 0.120; ANCOVA, $p=0.085)$. However, serum levels of anti-A $\beta$ were different (mean, SD: CN 0.121, 0.083; MCI 0.107, 0.086; pAD 0.207, 0.205; ANCOVA, $p=0.004$ ) among the three diagnostic groups. Mean $O D_{492 \mathrm{~nm}}$ obtained for anti-A $\beta$ was significantly higher in the pAD group than in the $C N(p=0.007)$ and $\mathrm{MCl}$ $(p=0.002)$ groups, while significant differences were not found between the $\mathrm{CN}$ and $\mathrm{MCl}$ groups $(p=0.65)$ (Figure 1).

The percentage of patients positive for anti-TBP $\left(\mathrm{OD}_{492 \mathrm{~nm}}\right.$ $\geq 0.143)$ in the $\mathrm{MCl}(11.5 \%)$ and $\mathrm{pAD}(24.1 \%)$ groups were significantly higher than those in the $\mathrm{CN}$ group $(6.1 \%)$ $\left(X^{2}=6.21, d f=2, p=0.044\right)$ (Figure 1a). There were no significant differences in the percentage of individuals positive for anti-ALD $\left(O D_{492 \mathrm{~nm}} \geq 0.139\right)$ among the three groups (pAD 24.1\%, $\mathrm{MCl} 23.1 \%, \mathrm{CN} 6.1 \%, \mathrm{X}^{2}=4.99$, df $=2$, $p=0.082)$ (Figure $1 b)$. The percentage of anti-A $\beta(19 \%)$ in pAD-group patients $\left(O D_{492 n m}>0.245\right)$ was significantly higher than those in the $\mathrm{MCl}(4 \%)$ and $\mathrm{CN}(9.1 \%)$ groups, $\left(\mathrm{X}^{2}=6.19\right.$, $\mathrm{df}=2$, $p=0.045)$ (Figure 1c).

Comparison of predictive power For each diagnostic method, the respective ROCs were constructed and sensitivity and specificity values determined, choosing a cutoff point to maximize the Youden index (sensitivity + specificity - 1).[50]

The predictive power of anti-A $\beta$ and anti-ALD values obtained in the assays was assessed by analyzing their ROC curves (Figure 2 ). Determination of serum levels of anti-A $\beta$ showed sensitivity of $67 \%$ and specificity of $63 \%$ (AUC, $0.70 ; 95 \% \mathrm{Cl} 0.59-0.79$ ). Subsequent analysis compared diagnostic accuracy with preset

Figure 1: Serum antibody levels by diagnostic group

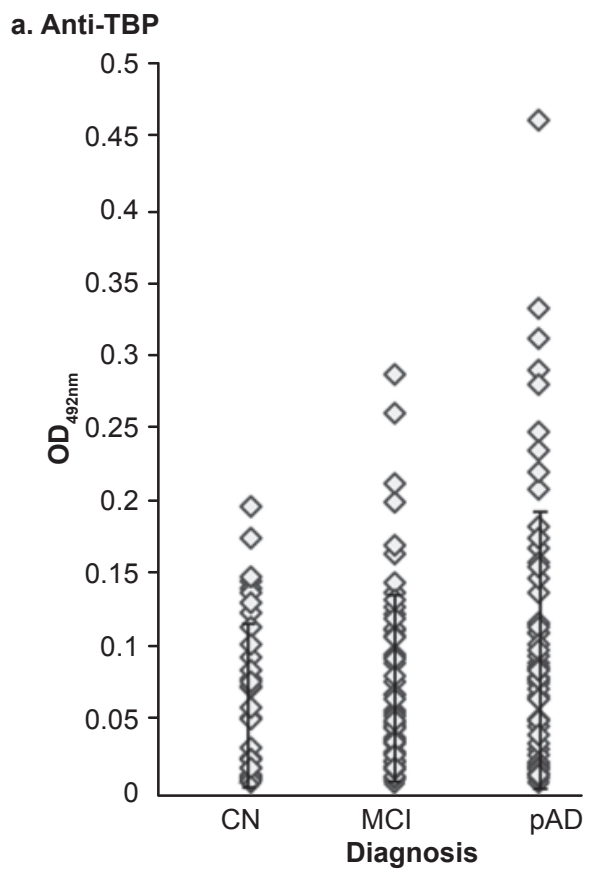

$A \beta$ : amyloid beta

$O D_{492 n m}$ : optical density units at $492 \mathrm{~nm}$ b. Anti-ALD

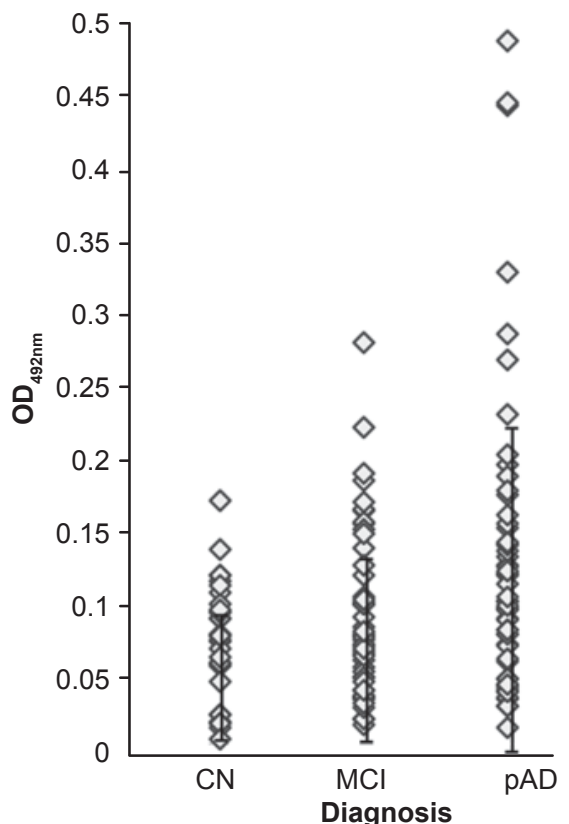

ALD: aldolase pAD: probable Alzheimer disease c. Anti-A $\beta$

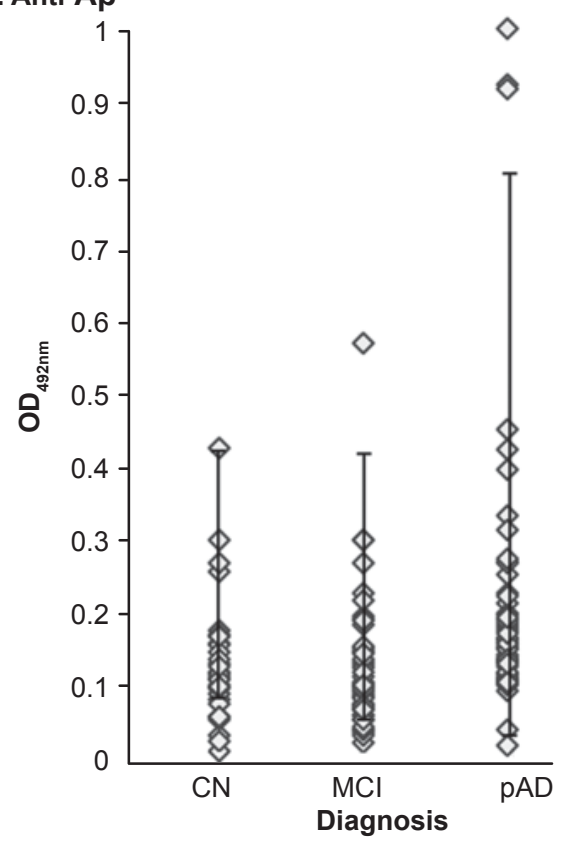

$\mathrm{CN}$ : cognitively normal TBP: total brain protein

MCl: mild cognitive impairment 
Figure 2: ELISA ROC curves for serum levels of anti-A $\beta$, anti-ALD and anti-TBP

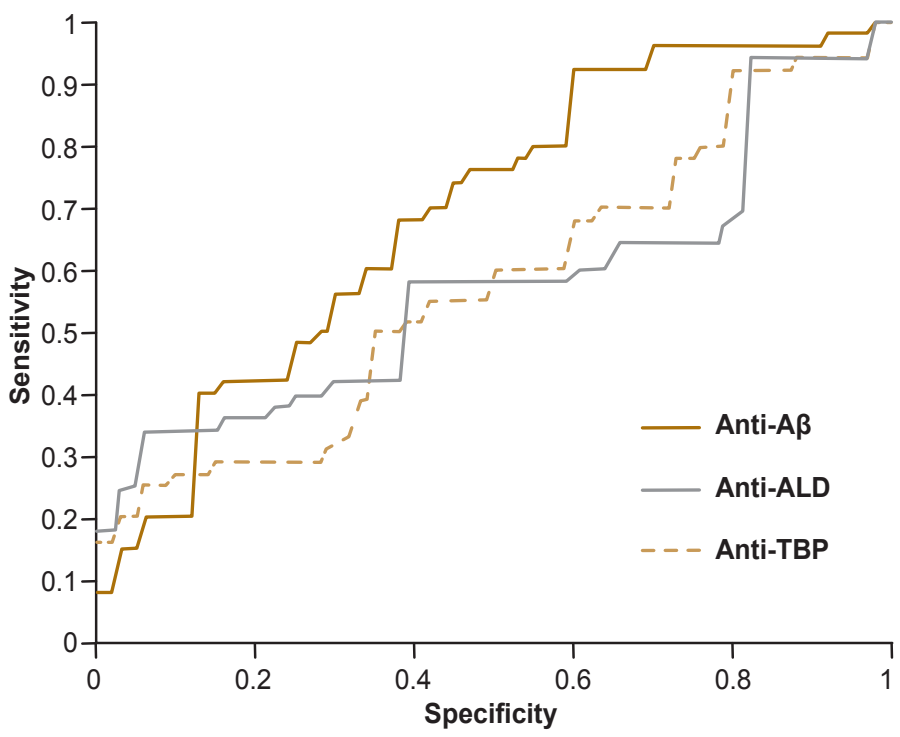

A $\beta$ : amyloid beta ALD: aldolase TBP: total brain protein

cutoff points of $80 \%$ for sensitivity and specificity. For $80 \%$ sensitivity, specificity was $45 \%$, and for $80 \%$ specificity, sensitivity was $41 \%$. The assay used to determine serum levels of anti-ALD had $55 \%$ sensitivity and $60 \%$ specificity (AUC $0.57,95 \% \mathrm{Cl} 0.46$ -0.67 ) with sensitivity of $34 \%$ and specificity of $21 \%$, with their counterpart set at $80 \%$. Finally, the assay used for to determine serum anti-TBP levels had $48 \%$ sensitivity and $63 \%$ specificity (AUC $0.58,95 \% \mathrm{Cl} 0.47-0.68$ ), with sensitivity of $27 \%$ and specificity of $27 \%$ with their counterpart set at $80 \%$.

\section{DISCUSSION}

It is important to have biomarkers as diagnostic resources for early and presymptomatic identification of patients with $A D$, to facilitate decisions on individualized treatment and followup, as well as to improve development of drugs for this disorder. The diagnostic process begins with tests that have high sensitivity but low specificity (and low cost) and continues with other more specific ones useful for longitudinal quantification of the benefit of a given treatment. Biomarkers for $A D$ should be directly correlated with the disease's pathophysiology. They may be compounds obtained from body fluids or tissues (such as the tests described in cerebrospinal fluid) or brain images. This was a cross-sectional pilot study that enabled us to propose evaluation of a biomarker associated to formation of $A \beta$ plaques. Our literature review found no such studies in Latin America or the Caribbean.

Serum levels of anti-TBP, anti-ALD and anti-A $\beta$ Similarly to Levin's findings,[23] we detected no significant differences between anti-TBP levels in $\mathrm{CN}$ individuals and those with $\mathrm{MCl}$ or pAD. However, the percentage of positive individuals in the pAD group is significantly higher than in the $\mathrm{CN}$ and $\mathrm{MCl}$ groups. This suggests a possible relationship of anti-TBP with AD and is compatible with the mechanism proposed by Nagele[25] to explain the possible contribution of serum anti-TBP to AD pathogenesis: binding anti-A $\beta$ to the neuronal surface activates receptor-mediated endocytosis, facilitating internalization and chronic accumulation of $A \beta$, which eventually causes neuronal death and release of amyloid aggregates into the extracellular space.

On the other hand, Mor identified aldolase as the main autoantigen in patients with $A D,[27]$ a result inconsistent with the lack of significant differences between cognitively normal patients and the others in mean anti-ALD levels and percentage of anti-ALD positivity. It has been argued that anti-ALD could be derived from autoimmunization due to ongoing neuronal damage during $A D$ development. The inhibitory activity of $A D$ patients' sera on aldolase enzyme activity observed by Mor[27] led him to theorize that anti-ALD could enter living neurons and affect ATP production. While Douglas proved that internalization of intracellular antiTBP in susceptible neurons is possible via Fcy receptors, and described its harmful effects,[51] Mor's work did not confirm the ability of anti-ALD to enter living neurons, nor did it assess the effect of anti-ALD sera or Abs on energy metabolism in neuron cultures.[27]

Since Mor's is the only work that describes a relationship between AD and serum levels of anti-ALD,[27] there is limited scope for assessing the reproducibility of our results. However, Dale found increased levels of anti-ALD in patients with pediatric autoimmune neuropsychiatric disorders associated with streptococcal infections (PANDAS), and there were indications that these Abs could even become pathogenic, causing cell apoptosis.[45] The absence of homology between human neuronal aldolase and the aldolase of Streptococcus pyogenes rules out, the possibility that anti-ALD were caused by molecular mimicry in that study.

Given this background, it is likely that anti-ALD are the result of autoimmunization resulting from neuronal damage, and not primary immunological components in the pathogenesis of PANDAS and $A D$. Even so, anti-ALD could be useful as biomarkers of neuronal damage, to monitor neurological impairment associated with different diseases.

Natural anti-A $\beta$ have generated great interest as $A D$ biomarkers because they are detected in both serum and CSF.[25,30-32] Some authors attribute a protective role to them, because of their effects on $A \beta$ elimination in transgenic mice,[52] and their neuroprotective activity.[22] Others consider them risk factors, due to the correlation detected between anti-A $\beta$ plasma levels and $A \beta$ deposits in the brain.[25] There is great heterogeneity in reports on serum levels of anti-A $\beta$ in $A D$ patients and there is still no consensus on the nature of their relationship to the disease. [53-57]

Discrepancies in these results could be a product of different experimental designs and possible underestimation of serum levels of anti-A $\beta$, because those that form immunocomplexes in blood are undetectable. Gustaw-Rothenberg reported a higher level of anti-A $\beta$ in serum of $A D$ patients by performing acidic dissociation of immunocomplexes,[53] and Storace detected elevated serum levels of anti-A $\beta$ in patients with $\mathrm{MCl}$ who progressed to AD.[54] However, even results of studies using acid dissociation are heterogeneous; e.g., Klaver's replication failed to find such differences.[55] 
Maftei examined serum from healthy adults aged 18-89 years and found that immunocomplexes were more abundant than free anti- $A \beta$ and their levels significantly higher in patients with AD.[56] This was consistent with Gustaw-Rothenberg's findings using acid dissociation[53] and Mruthinti's using immunopurification of serum anti-A $\beta$ ),[57] as well as with our results using sandwich ELISA. Our finding that mean $\mathrm{OD}_{492 n \mathrm{~mm}}$ for anti-A $\beta$ and percentage of anti-A $\beta$ positivity were significantly higher in the pAD group than in the CN group is consistent with Nath's conclusion about the ability of anti- $A \beta$ to magnify $A \beta$ 's neurotoxicity.[32]

Unlike previous studies,[53-57] ours used natural murine $A \beta$ as substitute for synthetic $A \beta$. According to Dale, autoantibodies developed in patients equally recognize human or murine neuroantigens,[45] making murine $A \beta$ an acceptable alternative to synthetic $A \beta$ or natural human $A \beta$.

In the sandwich ELISA design we employed, natural murine $A \beta$ is captured by a commercial anti-A $\beta$ (Sigma, A3981, USA) previously immobilized on ELISA plate wells (Figure 3 ). This commercial anti-A $\beta$ recognizes amino acid residues between positions 1 and 12 near the $\mathrm{N}$-terminal end of $A \beta$, whereas natural anti- $A \beta$ in human serum recognize amino acid residues between positions 21 and 37 near the C-terminal region.[52,56] In the sandwich ELISA we used, differential recognition (without interference) of $A \beta$ by these two Abs was used to determine serum levels of anti-A $\beta$. This assay, unlike the ELISA developed by Maftei,[56] allows measurement of serum levels of free anti$A \beta$ and not those forming immunocomplexes.

Figure 3: Sandwich ELISA design for detection of serum anti-A $\beta$

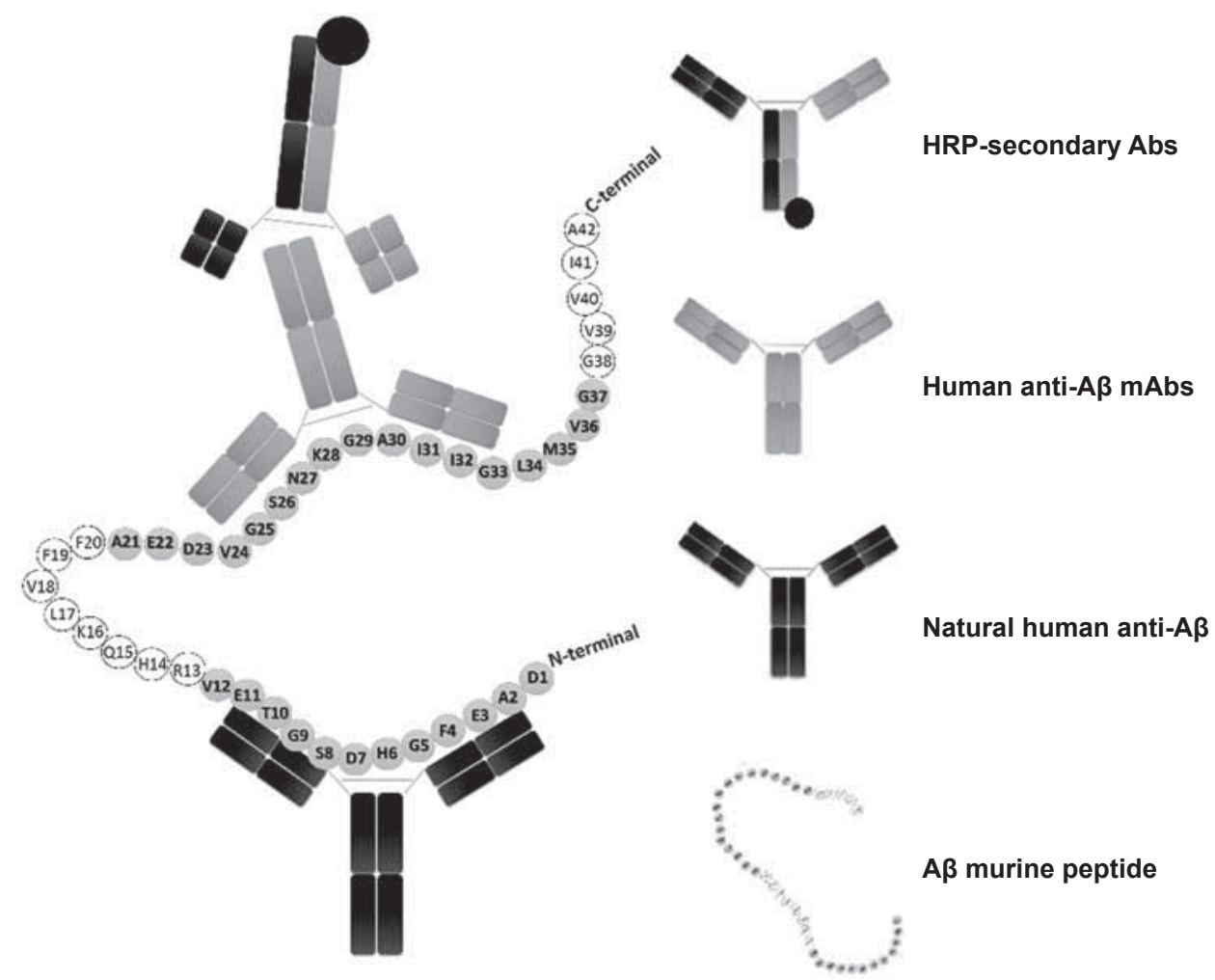

Abs: antibodies $\quad A \beta$ : beta amyloid HRP: horseradish peroxidase mAbs: monoclonal antibodies Note: Amino acids included in regions recognized by human and commercial anti-A $\beta$ are shown in a darker color with their corresponding antibodies.
In both ROC analysis and comparison of mean serum antibody levels, testing for anti-A $\beta$ was the only one with acceptable diagnostic properties for distinguishing between individuals with $P A D$ and those who were cognitively normal. Specificity and AUC values we obtained using ELISA for determination of anti-A $\beta$ are similar to those observed by Maftei,[56] suggesting the usefulness of both methods for molecular diagnosis of $A D$.

Several studies report alterations of serum levels of antiTBP in AD patients,[30-33] Such alterations could cause or predispose to development of $A D$;[25] or they could be due to autoimmunization resulting from cell damage induced by cytotoxicity of $A \beta$ plaques;[32] or they could be part of a protective immune response, by helping remove $A \beta$ plaques.[24] If they are to be used as biomarkers, it will be essential to clarify the precise nature of their relationship to $A D$.

The generally low percentages of individuals positive for antiTBP, anti-A $\beta$ and anti-ALD and the data dispersion found in this study could also have different explanations. They could be due to individuals in the AD group with low serum antibody levels in fact having another type of dementia; to loss of serum reactivity in some patients because of epitope or determinant dispersion; $[58,59]$ and/or to presence of $A \beta$-anti- $A \beta$ immunocomplexes[53] undetectable by the ELISA design we used. It is also worth pointing out that these same factors would affect ROC curve results. We propose validating the method with molecular imaging studies, which provide greater certainty in $A D$ diagnosis.

The ability of this ELISA to detect differences in serum levels of anti$A \beta$ among the three diagnostic groups suggests its usefulness for an alternative or complementary approach to previously reported direct ELISAs. [22-25] It does not require additional sample preparation steps, such as acid dissociation or immunopurification, and can provide information about anti-A $\beta$ 's affinity and the behavior of free Abs at different disease stages.

Study limitations and future directions Pilot studies such as this represent a fundamental phase in the research process, examining the feasibility of new methods intended for use in a larger study. It should be noted that pilot studies are not hypothesis testing, nor do they assess safety, efficacy or effectiveness. Because sample sizes are limited, they cannot provide reliable estimates of effect size for power calculations for later studies. What they can do is provide evidence of feasibility and identify changes needed in the experimental design.[60]

This study was limited by its small sample size and by differences in ethnic 
composition (for which distribution of skin color was considered a surrogate), so that participants may not be representative of the general population. It was also limited by its cross-sectional design. A confirmatory study with larger sample sizes and longitudinal followup is required to assess the effects of differing ethnic mix and determine the predictive value of anti-A $\beta$ levels for diagnosis and early detection of cognitive impairment and AD. It will also be necessary to include molecular imaging studies, in addition to neuropsychological diagnosis, to validate the diagnostic power of the method used.

\section{CONCLUSIONS}

Our results support a relationship between anti-A $\beta$ and $A D$ pathology. The diagnostic performance and predictive value of serum anti-A $\beta$ suggest they could be useful as biomarkers in early diagnosis of $A D$. A larger and more detailed study would clarify the relationships between $A D$ and such $A b s$, as well as their optimal use. Validation and improvement of this noninvasive method would have a substantial clinical impact, since it would permit population monitoring to identify vulnerable groups and improve prevention efforts. $-1 /$ -

\section{REFERENCES}

1. Prince M, Wimo A, Guerchet M, Ali GC, Wu YT. World Alzheimer Report 2015-The Global Impact of Dementia: An analysis of prevalence, incidence, cost and trends. London: Alzheimer's Disease International; 2015. $83 \mathrm{p}$

2. United Nations Population Division. World Population Ageing, 2015 [Internet]. New York: United Nations; 2015 [cited 2016 Apr 22]. 4 p. Available from: https://www.un.org/en/development/ desa/population/publications/pdf/ageing/Popula tionAgeingAndDevelopment2015.pdf

3. Duque-Castaño A, Roldán MI, Arango-Viana JC, Arcos-Burgos M, Cubillo H, Lopera F. [Neuropathological findings in early-onset Alzheimer's disease (E280a-PS1 mutation)]. Rev Neurol. 1999 Jul 1-15;29(1):1-6. Spanish.

4. Bertram L, Lill CM, Tanzi RE. The genetics of Alzheimer disease: back to the future. Neuron. 2010 Oct 21;68(2):270-81.

5. McKhann G, Drachman D, Folstein M, Katzman $R$, Price D, Stadlan EM. Clinical diagnosis of Alzheimer's disease: report of the NINCDSADRDA Work Group under the auspices of Department of Health and Human Services Task Force on Alzheimer's Disease. Neurology. 1984 Jul;34(7):939-44.

6. American Psychiatric Association. Diagnostic and statistical manual of mental disorder. 4th ed. Virginia: American Psychiatric Association; 1994 Jan 15. $886 p$

7. Folstein MF, Folstein SE, McHugh PR. "Minimental state". A practical method for grading the cognitive state of patients for the clinician. J Psychiatr Res. 1975 Nov;12(3):189-98.

8. Morris JC. The Clinical Dementia Rating (CDR): current version and scoring rules. Neurology. 1993 Nov;43(11):2412-4.

9. Beach TG, Monsell SE, Phillips LE, Kukull W. Accuracy of the clinical diagnosis of Alzheimer disease at National Institute on Aging Alzheimer Disease Centers, 2005-2010. J Neuropathol Exp Neurol. 2012 Apr;71(4):266-73.

10. Farrer LA, Cupples LA, Haines JL, Hyman B, Kukull WA, Mayeux R, et al. Effects of age, sex, and ethnicity on the association between apolipoprotein E genotype and Alzheimer disease. A meta-analysis. APOE and Alzheimer Disease Meta Analysis Consortium. JAMA. 1997 Oct 22-29;278(16):1349-56.

11. National Health Statistics and Medical Records Division (CU). Anuario Estadístico de Salud 2015 [Internet]. Havana: Ministry of Public Health (CU); 2016 Apr 22 [cited 2017 Mar 27]. Available from: http://files.sld.cu/dne/ files/2016/04/Anuario_2015_electronico-1 .pdf. Spanish.

12. National Health Statistics and Medical Records Division (CU). Anuario Estadístico de Salud 2009 [Internet]. Havana: Ministry of Public Health (CU); 2010 [cited 2017 Mar 27]. 243 p. Available from: http://files.sld.cu/dne/files/2010/04/anuario -2009e3.pdf. Spanish.
13. Llibre J. Prevenir la enfermedad de Alzheimer. Havana: Editorial Científico-Técnica; 2009. Spanish.

14. Llibre JJ, Valhuerdi A, Calvo M, García RM, Guerra M, Laucerique T, et al. Dementia and other chronic diseases in older adults in Havana and Matanzas: the 10/66 study in Cuba. MEDICC Rev. 2011Oct;13(4):30-7.

15. Llibre JJ, Fernández Y, Marcheco B, Contreras N, López AM, Otero M. Prevalence of Dementia and Alzheimer's Disease in a Havana Municipality: A Community-Based Study among Elderly Residents. MEDICC Rev. 2009 Apr;11(2):29-35.

16. Llibre Rodríguez J, Valhuerdi A, Sánchez II, Reyna C, Guerra MA, Copeland JR, et al. The prevalence, correlates and impact of dementia in Cuba. A 10/66 group population-based survey. Neuroepidemiology. 2008;31(4): 243-51.

17. Llibre-Rodríguez JJ, Valhuerdi-Cepero A, LópezMedina AM, Noriega-Fernández L, Porto-Álvarez R, Guerra-Hernández MA, et al. Cuba's Aging and Alzheimer Longitudinal Study. MEDICC Rev. 2017 Jan;19(1):31-5.

18. Teruel BM, Rodríguez JJ, McKeigue P, Mesa TC, Fuentes E, Cepero AV, et al. Interactions between genetic admixture, ethnic identity, APOE genotype and dementia prevalence in an admixed Cuban sample; a cross-sectional population survey and nested case-control study. BMC Med Genet. 2011 Mar 24;12:43. DOI: 10.1186/14712350-12-43.

19. Llibre JJ. Envejecimiento y demencia: implicaciones para la comunidad científica, la salud pública y la sociedad cubana. Anales Acad Ciencias Cuba. 2012;2(2). Spanish

20. Prince M, Acosta D, Ferri CP, Guera M, Huang Y, Llibre Rodríguez JJ, et al. Dementia incidence and mortality in middle-income countries, and associations with indicators of cognitive reserve: a 10/66 Dementia Research Group population-based cohort study. Lancet. 2012 Jul 7;380(9836):50-8.

21. Eikelenboom P, van Exel E, Veerhuis R, Rozemuller AJ, van Gool WA, Hoozemans JJ. Innate immunity and the etiology of late-onset Alzheimer's disease. Neurodegener Dis. 2012;10(14):271-3.

22. Bouras C, Riederer BM, Kövari E, Hof PR, Giannakopoulos P. Humoral immunity in brain aging and Alzheimer's disease. Brain Res Brain Res Rev. 2005 Jun;48(3):477-87.

23. Levin EC, Acharya NK, Han M, Zavareh SB, Sedeyn JC, Venkataraman V, et al. Brain-reactive autoantibodies are nearly ubiquitous in human sera and may be linked to pathology in the context of blood-brain barrier breakdown. Brain Res. 2010 Jul 23;1345:221-32.

24. D'Andrea MR. Evidence linking neuronal cell death to autoimmunity in Alzheimer's disease. Brain Res. 2003 Aug 22;982(1):19-30

25. Nagele RG, Clifford PM, Siu G, Levin EC, Acharya NK, Han M, et al. Brain-reactive auto- antibodies prevalent in human sera increase intraneuronal amyloid-beta(1-42) deposition. J Alzheimers Dis. 2011;25(4):605-22.

26. Gruden MA, Davidova TB, Malisauskas M Sewell RD, Voskresenskaya NI, Wilhem K, et al. Differential neuroimmune markers to the onset of Alzheimer's disease neurodegeneration and dementia: autoantibodies to Abeta ((25-35)) oligomers, S100b and neurotransmitters. J Neuroimmunol. 2007 May;186(1-2):181-92.

27. Mor F, Izak M, Cohen IR. Identification of aldolase as a target antigen in Alzheimer's disease. J Immunol. 2005 Sep 1;175(5):3439-45.

28. Hatzifilippou E, Koutsouraki E, Banaki T, Traka M, Costa VG, Baloyannis SJ. Antibodies against GM1 in demented patients. Am J Alzheimers Dis Other Demen. 2008 Jun-Jul;23(3):274-9.

29. Kankaanpaä J, Turunen SP, Moilanen V, Hörkkö $\mathrm{S}$, Remes AM. Cerebrospinal fluid antibodies to oxidized LDL are increased in Alzheimer's disease. Neurobiol Dis. 2009 Mar;33(3):467-72.

30. Kellner A, Matschke J, Bernreuther C, Moch H, Ferrer I, Glatzel M. Autoantibodies against betaamyloid are common in Alzheimer's disease and help control plaque burden. Ann Neurol. 2009 Jan;65(1):24-31.

31. Brettschneider $S$, Morgenthaler NG, Teipel SJ, Fischer-Schulz C, Bürger K, Dodel R, et al. Decreased serum amyloid beta (1-42) autoantibody levels in Alzheimer's disease, determined by a newly developed immuno-precipitation assay with radiolabeled amyloid beta(1-42) peptide. Biol Psychiatry. 2005 Apr 1;57(7):813-6.

32. Nath A, Hall E, Tuzova M, Dobbs M, Jons M Anderson $\mathrm{C}$, et al. Autoantibodies to amyloid beta-peptide (Abeta) are increased in Alzheimer's disease patients and Abeta antibodies can enhance Abeta neurotoxicity: implications for disease pathogenesis and vaccine development. Neuromolecular Med. 2003;3(1):29-39.

33. Butterfield DA, Swomley AM, Sultana R. Amyloid beta-peptide (1-42)-induced oxidative stress in Alzheimer disease: importance in disease pathogenesis and progression. Antioxid Redox Signal. 2013 Sep 10;19(8):823-35.

34. Walker LC, Jucker M. Neurodegenerative diseases: expanding the prion concept. Annu Rev Neurosci. 2015 Jul 8;38:87-103.

35. Colasanti T, Barbati C, Rosano G, Malorni W, Ortona E. Autoantibodies in patients with Alzheimer's disease: pathogenetic role and potential use as biomarkers of disease progression. Autoimmun Rev. 2010 Oct;9(12):807-11.

36. Jack CR Jr, Bernstein MA, Borowski BJ, Gunter JL, Fox NC, Thompson PM, et al. Update on the magnetic resonance imaging core of the Alzheimer's disease neuroimaging initiative. Alzheimers Dement. 2010 May;6(3):212-20.

37. Kantarci K. Molecular imaging of Alzheimer disease pathology. Am J Neuroradiol. 2014 Jun;35(6 Suppl):S12-7. 
38. Blennow K, Dubois B, Fagan AM, Lewczuk P, de Leon MJ, Hampel H. Clinical utility of cerebrospinal fluid biomarkers in the diagnosis of early Alzheimer's disease. Alzheimers Dement. 2015 Jan;11(1):58-69.

39. Jack CR Jr, Knopman DS, Jagust WJ, Petersen RC, Weiner MW, Aisen PS, et al. Tracking pathophysiological processes in Alzheimer's disease: an updated hypothetical model of dynamic biomarkers. Lancet Neurol. 2013 Feb;12(2):207-16.

40. Wenham PR, Price WH, Blandell G. Apolipoprotein $\mathrm{E}$ genotyping by one-stage PCR. Lancet. 1991 May 11;337(8750):1158-9.

41. Suárez VM, Fernández $\mathrm{Y}$, López Edel $\mathrm{C}$, Clarke $\mathrm{DH}$, Bobes MA, Riverón AM, et al. Apolipoprotein $\mathrm{E}$ alleles in Cuban patients with mild cognitive impairment. Am J Alzheimers Dis Other Demen. 2014 May;29(3):236-41.

42. Petersen RC. Mild cognitive impairment as a diagnostic entity. J Intern Med. 2004;256(3):183-94.

43. Coit P, Ognenovski M, Gensterblum E, Maksimowicz-McKinnon K, Wren JD, Sawalha AH. Ethnicity-specific epigenetic variation in naive CD4+ T cells and the susceptibility to autoimmunity. Epigenetics Chromatin. 2015 Nov 24;8:49.

44. Ericsson C, Peredo I, Nistér M. Optimized protein extraction from cryopreserved brain tissue samples. Acta Oncol. 2007;46(1):10-20.

45. Dale RC, Candler PM, Church AJ, Wait R, Pocock JM, Giovanni J. Neuronal surface glycolytic enzymes are autoantigen targets in post-streptococcal autoimmune CNS disease. J Neuroimmunol. 2006 Mar;172(1-2):187-97.

46. Crowther JR. Methods in Molecular Biology. The ELISA guide book. Vol. 42. New York: Humana Press; 2009. $566 \mathrm{p}$

47. Vadasz Z, Haj T, Kessel A, Toubi E. Age-related autoimmunity. BMC Med. 2013 Apr 4;11:94.

48. Franco-Marina F, García-González JJ, WagnerEcheagaray F, Gallo J, Ugalde O, Sánchez-García S, et al. The Mini-mental State Examination revisited: ceiling and floor effects after score adjustment for educational level in an aging Mexican population. Int Psychogeriatr. 2010 Feb;22(1):72-81.

49. Hanley JA, McNeil BJ. A method of comparing the areas under receiver operating characteristic curves derived from the same cases. Radiology. 1983 Sep;148(3):839-43.

50. Cerda J, Cifuentes L. [Using ROC curves in clinical investigation: theoretical and practical issues]. Rev Chilena Infectol. 2012 Apr;29(2):13841. Spanish.

51. Douglas JN, Gardner LA, Levin MC. Antibodies to an intracellular antigen penetrate neuronal cells and cause deleterious effects. J Clin Cell Immunol. 2013 Jan 30;4(1).
52. Dodel R, Balakrishnan K, Keyvani K, Deuster O Neff F, Andrei-Selmer LC, et al. Naturally occurring autoantibodies against beta-amyloid: investigating their role in transgenic animal and in vitro models of Alzheimer's disease. J Neurosci. 2011 Apr 13;31(15):5847-54.

53. Gustaw-Rothenberg KA, Siedlak SL, Bonda DJ, Lerner A, Tabaton M, Perry G, et al. Dissociated amyloid-beta antibody levels as a serum biomarker for the progression of Alzheimer's disease: a population-based study. Exp Gerontol. 2010 Jan; 45(1):47-52.

54. Storace D, Cammarata S, Borghi R, Sanguineti $\mathrm{R}$, Giliberto L, Piccini A, et al. Elevation of \{beta\}amyloid 1-42 autoantibodies in the blood of amnestic patients with mild cognitive impairment. Arch Neurol. 2010 Jul;67(7):867-72.

55. Klaver AC, Coffey MP, Smith LM, Bennett DA Finke JM, Dang L, et al. ELISA measurement of specific non-antigen-bound antibodies to Abeta1-42 monomer and soluble oligomers in sera from Alzheimer's disease, mild cognitively impaired, and noncognitively impaired subjects. J Neuroinflammation. 2011 Aug 9;8:93.

56. Maftei M, Thurm F, Schnack C, Tumani H, Otto $M$, Elbert $T$, et al. Increased levels of antigenbound beta-amyloid autoantibodies in serum and cerebrospinal fluid of Alzheimer's disease patients. PLoS One. 2013 Jul 18;8(7):e68996.

57. Mruthinti S, Buccafusco JJ, Hill WD, Waller JL, Jackson TW, Zamrini EY, et al. Autoimmunity in Alzheimer's disease: increased levels of circulating lgGs binding Abeta and RAGE peptides. Neurobiol Aging. 2004 Sep;25(8):1023-32.

58. Tuohy VK, Kinkel RP. Epitope spreading: a mechanism for progression of autoimmune disease. Arch Immunol Ther Exp (Warsz) 2000;48(5):347-51

59. Weisman D, Hakimian E, Ho GJ. Interleukins, inflammation, and mechanisms of Alzheimer's disease. Vitam Horm. 2006;74:505-30.

60. Leon AC, Davis LL, Kraemer HC. The role and interpretation of pilot studies in clinical research. J Psychiatr Res. 2011 May;45(5):626-9.

\section{THE AUTHORS}

Leonardo Cristiá-Lara, biochemist and molecular biologist, Cuban Neuroscience Center (CNEURO), Havana, Cuba.

Saily Sosa-Pérez, internist with a master's degree in healthy aging, Iván Portuondo General Teaching Hospital (HGDIP), Havana, Cuba.
Nelky Urrutia-Amble, psychologist, HGDIP, Havana, Cuba.

Alia Garrudo-Guirado, mathematician, CNEURO, Havana, Cuba.

Aimé Posada-García, biologist, HGDIP, Havana, Cuba.

Lídice Galán-García, mathematician, CNEURO, Havana, Cuba.

Levis Verde-Corvo, nurse with a master's degree in comprehensive child health, HGDIP, Havana, Cuba.

Madelín Rodríguez-Morera, family physician with a master's degree in comprehensive child health, HGDIP, Havana, Cuba.

Miriam Dorestes-Brown, biology technician, CNEURO, Havana, Cuba.

Maria Antonieta Bobes-León, psychologist, CNEURO, Havana, Cuba.

Chryslaine Rodríguez-Tanty, chemist, CNEURO, Havana, Cuba.

Marquiza Sablón-Carrazana, chemist, CNEURO, Havana, Cuba.

Viana Manrique-Suárez (Corresponding author: vianalacubana1@gmailcom), biochemist and molecular biologist, CNEURO, Havana, Cuba.

Submitted: July 21, 2016

Approved for publication: April 7, 2017

Disclosures: None 